\title{
Preoxygenation before intubation in adult patients with acute hypoxemic respiratory failure: a network meta-analysis of randomized trials
}

\author{
Ka Man Fong ${ }^{*}$ (D), Shek Yin Au and George Wing Yiu Ng
}

\begin{abstract}
Background: Patients with acute hypoxemic respiratory failure are at risk for life-threatening complications during endotracheal intubation. Preoxygenation might help reduce the risk of hypoxemia and intubation-related complications. This network meta-analysis summarizes the efficacy and safety of preoxygenation methods in adult patients with acute hypoxemic respiratory failure.

Methods: We searched PubMed, EMBASE, and the Cochrane Library Central Register of Controlled Trials through April 2019 for randomized controlled trials (RCT) that studied the use of conventional oxygen therapy (COT), highflow nasal cannula (HFNC), noninvasive ventilation (NIV), and HFNC and NIV as preoxygenation before intubation in patients with acute hypoxemic respiratory failure. Citations' screening, study selection, data extraction, and risk of bias assessment were independently performed by two authors. The primary outcome was the lowest $\mathrm{SpO}_{2}$ during the intubation procedure.

Results: We included 7 RCTs (959 patients). Patients preoxygenated with NIV had significantly less desaturation than patients treated with COT (mean difference, MD 5.53, 95\% Cl 2.71, 8.34) and HFNC (MD 3.58, 95\% Cl 0.59, 6.57). Both NIV (odds ratio, OR $0.43,95 \% \mathrm{Cl} 0.21,0.87$ ) and HFNC (OR $0.49,95 \% \mathrm{Cl} 0.28,0.88$ ) resulted in a lower risk of intubation-related complications than COT. There were no significant mortality differences among the use of NIV, HFNC, COT, and HFNC and NIV during preoxygenation.

Conclusions: In adult patients with acute hypoxemic respiratory failure, NIV is a safe and probably the most effective preoxygenation method.
\end{abstract}

Keywords: Respiratory failure, Noninvasive ventilation, High flow nasal cannula, Preoxygenation, Meta-analysis

\section{Background}

Patients with acute hypoxemic respiratory failure are at increased risk for life-threatening complications during endotracheal intubation. Profound desaturation $\left(\mathrm{SpO}_{2}<\right.$ $80 \%$ ) during intubation was reported in $25 \%$ of patients [1]. Cardiac arrest occurred in 1 out of 40 intubations, and it was associated with hypoxemia and absence of preoxygenation [2]. Preoxygenation might help reduce the risk of hypoxemia and intubation-related complications.

\footnotetext{
* Correspondence: ckmfong@gmail.com

Department of Intensive Care, Queen Elizabeth Hospital, 30 Gascoigne Road, Kowloon, Hong Kong SAR
}

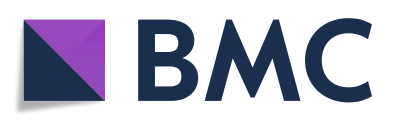

(c) The Author(s). 2019 Open Access This article is distributed under the terms of the Creative Commons Attribution 4.0 International License (http://creativecommons.org/licenses/by/4.0/), which permits unrestricted use, distribution, and reproduction in any medium, provided you give appropriate credit to the original author(s) and the source, provide a link to the Creative Commons license, and indicate if changes were made. The Creative Commons Public Domain Dedication waiver (http://creativecommons.org/publicdomain/zero/1.0/) applies to the data made available in this article, unless otherwise stated.
Apart from conventional oxygen therapy (COT) delivered through bag-valve mask or face mask, noninvasive ventilation (NIV) and high-flow nasal cannula (HFNC) have been increasingly used in the intensive care units (ICU) as preoxygenation devices. Both HFNC [3-5] and NIV [6, 7] have been shown to offer better preoxygenation than COT. The recently published FLORALI-2 study comparing HFNC and NIV has added new insight to this battlefield [8].

Network meta-analysis (NMA) has been increasingly advocated in medical research [9]. Through a combination of direct and indirect estimates of effects, NMA allows comparison of multiple interventions and improved precision. The aim of this NMA is to evaluate the impact of 
preoxygenation, which includes desaturation during intubation, intubated-related complications, and mortality, by various devices including COT, HFNC, and NIV, in adults with acute hypoxemic respiratory failure.

\section{Methods}

We adhered to the Preferred Reporting Items for Systematic Reviews and Meta-analyses extension statement for reporting network meta-analyses (PRISMANMA) (Additional file 1) [10]. The protocol for this review was registered in the International Prospective Register of Systematic Reviews (CRD42018085866).

\section{Data sources and searches}

We searched PubMed, EMBASE, and the Cochrane Library Central Register of Controlled Trials through April 2019 for potentially relevant studies published in English. Our PubMed search strategy is presented in Additional file 2: Table S1. Reference lists of relevant articles were also reviewed. We included randomized controlled trials (RCT) of adult patients with acute hypoxemic respiratory failure investigating any form of preoxygenation devices during endotracheal intubation. Acute hypoxemic respiratory failure was defined by the individual authors in the included studies. Preoxygenation devices included COT via bag-valve mask or face mask, HFNC, or NIV. We defined preoxygenation as oxygen delivery during the period before induction of anesthesia, till initiation of laryngoscopy. Apneic oxygenation was defined as oxygen delivery to the nasopharynx during the time between initiation of laryngoscopy to the intubation of the trachea (Additional file 2: Figure S1). We excluded studies focusing only on apneic oxygenation. The following were excluded: studies evaluating only the duration of preoxygenation, decision on ventilation or preoxygenation during anesthesia or interventional procedures, or enrolling healthy volunteers or animals.

\section{Study selection and data extraction}

Two authors (KF and SA) independently screened citations and abstracts in duplicate and independently. All references judged potentially relevant were evaluated for full-text eligibility. Discrepancies were solved by consensus with the

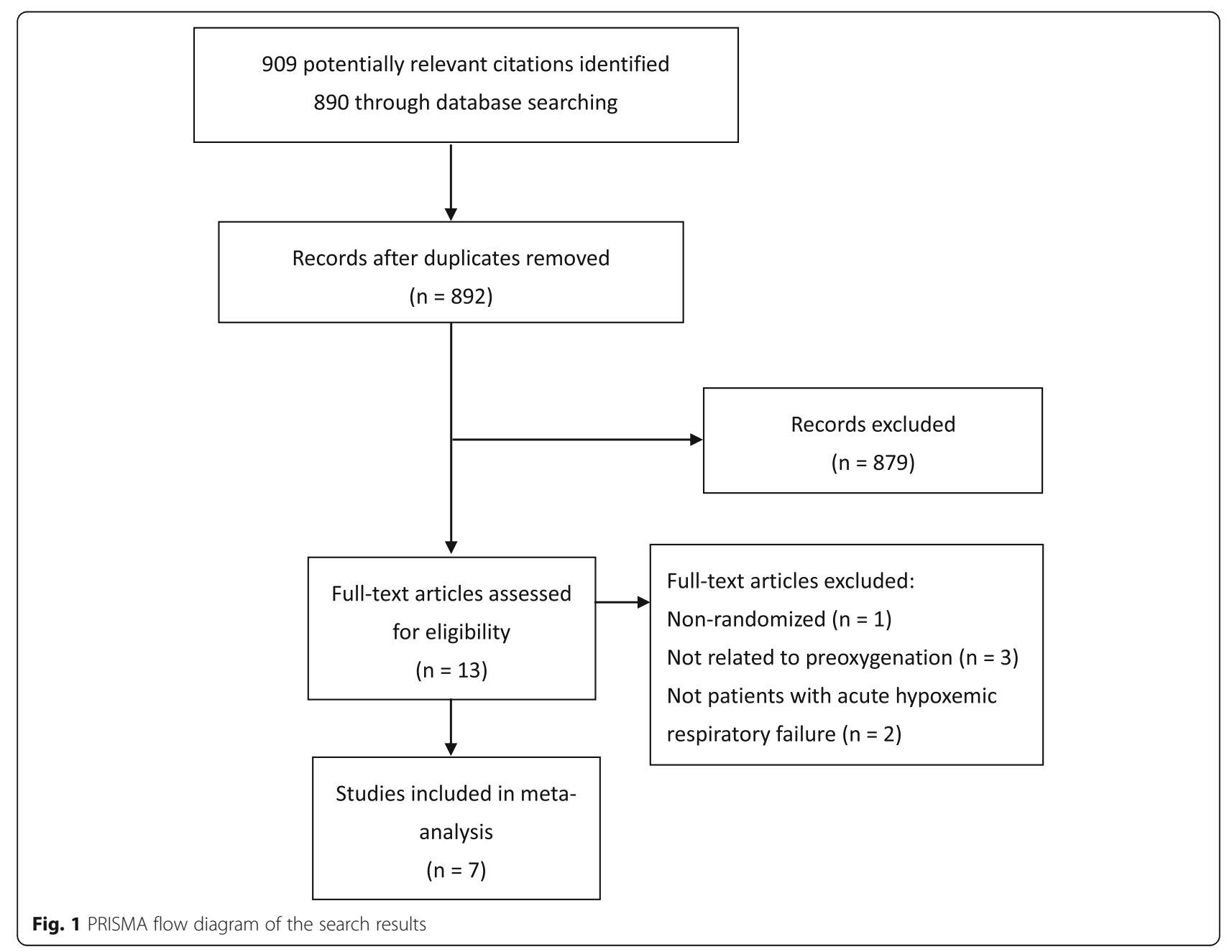




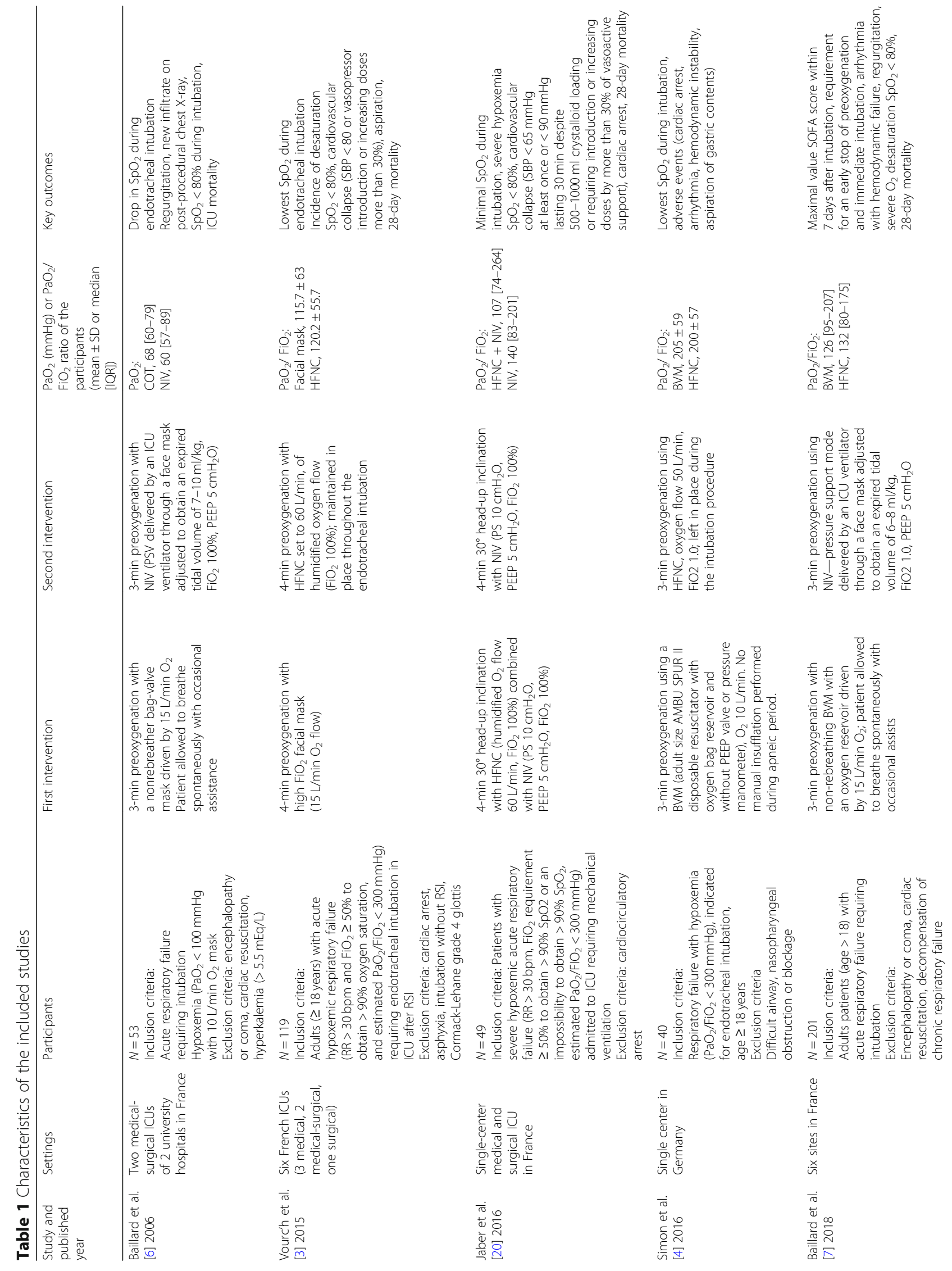




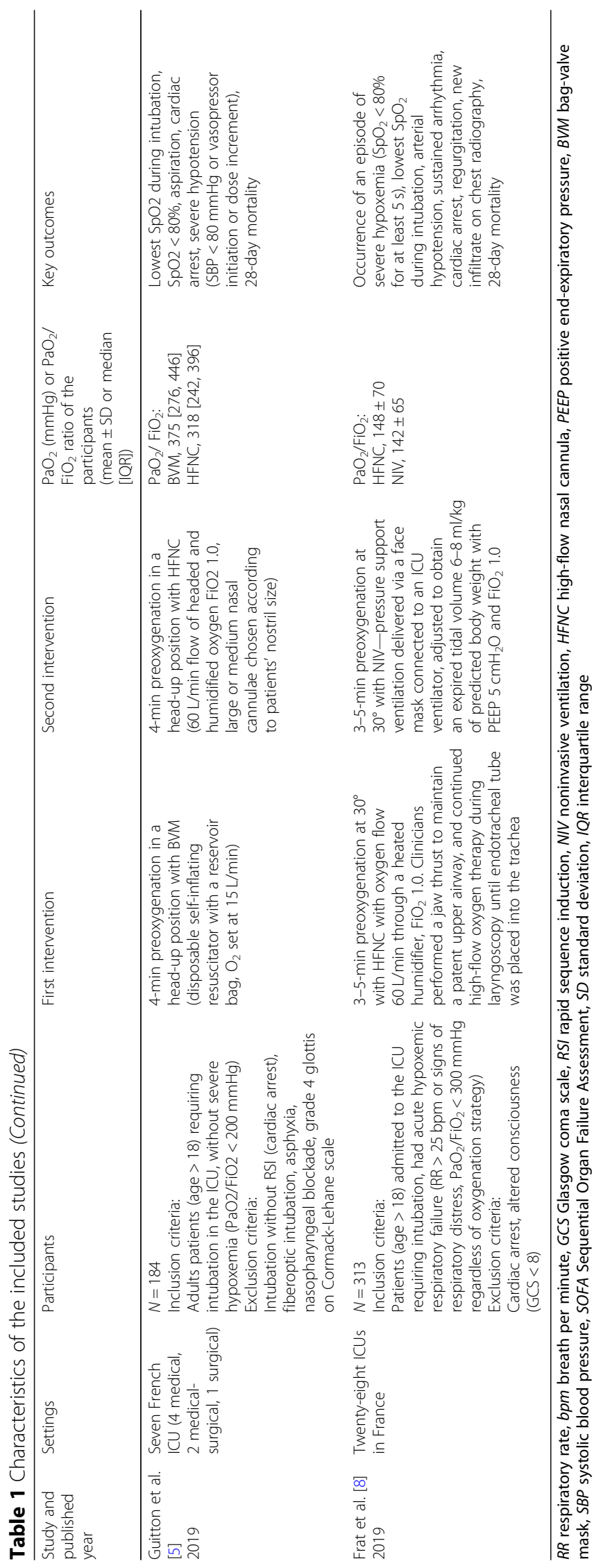




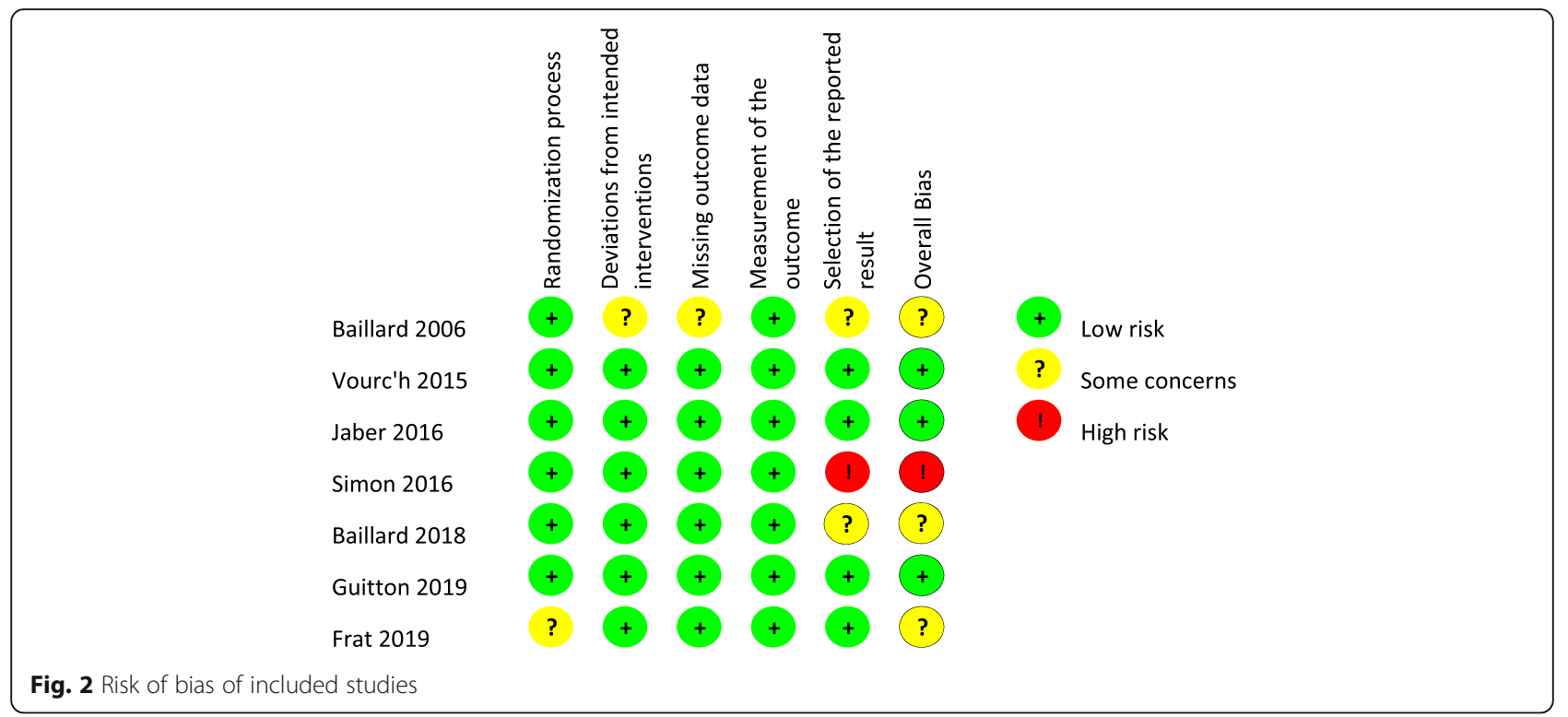

third author (GN). When relevant data or information was missing, we attempted to contact authors of the studies.

\section{Outcome measures}

The primary outcome was the lowest $\mathrm{SpO}_{2}$ during the intubation procedure (from beginning of laryngoscopy to confirmation of endotracheal intubation by capnography). The secondary outcomes were proportion of patients with severe desaturation $\left(\mathrm{SpO}_{2}<80 \%\right)$, intubation-related complications (aspiration or new infiltrate on post-intubation chest radiograph, hemodynamic instability, and cardiac arrest), and mortality.

\section{Risk of bias assessment}

Two authors (SA and GN) independently assessed the risk of bias of included studies. We assessed the risk of bias of RCTs using the revised Cochrane risk-ofbias tool for randomized trials [11]. In case of disagreement for the attribution of risk of bias, it was solved by discussion and consensus with the third author (KF).

\section{Statistical analysis and quality of evidence}

We performed a random effect network meta-analysis using a frequentist framework, calculating mean differences (MD) for continuous outcomes and odds ratios (OR) for dichotomous outcomes. Where data were not available, we converted the median and interquartile range to mean and standard deviations using a published equation [12].

We used the package "netmeta" (version 1.0-1) in $\mathrm{R}$ (version 3.4.2, The R Foundation for Statistical Computing) to perform network meta-analysis [13]. The "netmeta" package is based on an approach that follows the graph-theoretical methodology. We ranked the treatment using the $P$-score which are based on the frequentist point estimates and their standard errors [14]. It represented the extent of certainty that a treatment is better than the other treatments-the $P$-score would be close to 1 when a treatment is certain to be the best and close to 0 when a treatment was certain to be the worst. Precision of the ranking is also taken into account by looking at confidence intervals. Homogeneity and consistency assumptions were checked using a generalized Cochrane's Q statistics for multivariate meta-analysis [15]. Inconsistency in the random effect model was assessed by between-study $Q$ statistic that was calculated based on design-by-treatment interaction model [16]. Sensitivity analysis was conducted by sequentially omitting one study each time.

We applied the modified Grading of Recommendations Assessment, Development and Evaluation (GRADE) approach for network meta-analysis [17, 18]. The contribution of all direct estimates to the network estimates was evaluated from the contribution matrix [19]. We would rate down the quality of evidence when intransitivity was present, or when there was incoherence between direct and indirect estimates. When both direct and indirect evidence were available, we chose the higher of the two quality ratings for the NMA estimate [17].

\section{Results}

Literature search

The initial search yielded 909 citations; 13 proved potentially eligible after reviewing the full-text articles. Seven studies met our inclusion criteria, representing 959 patients (Fig. 1). 


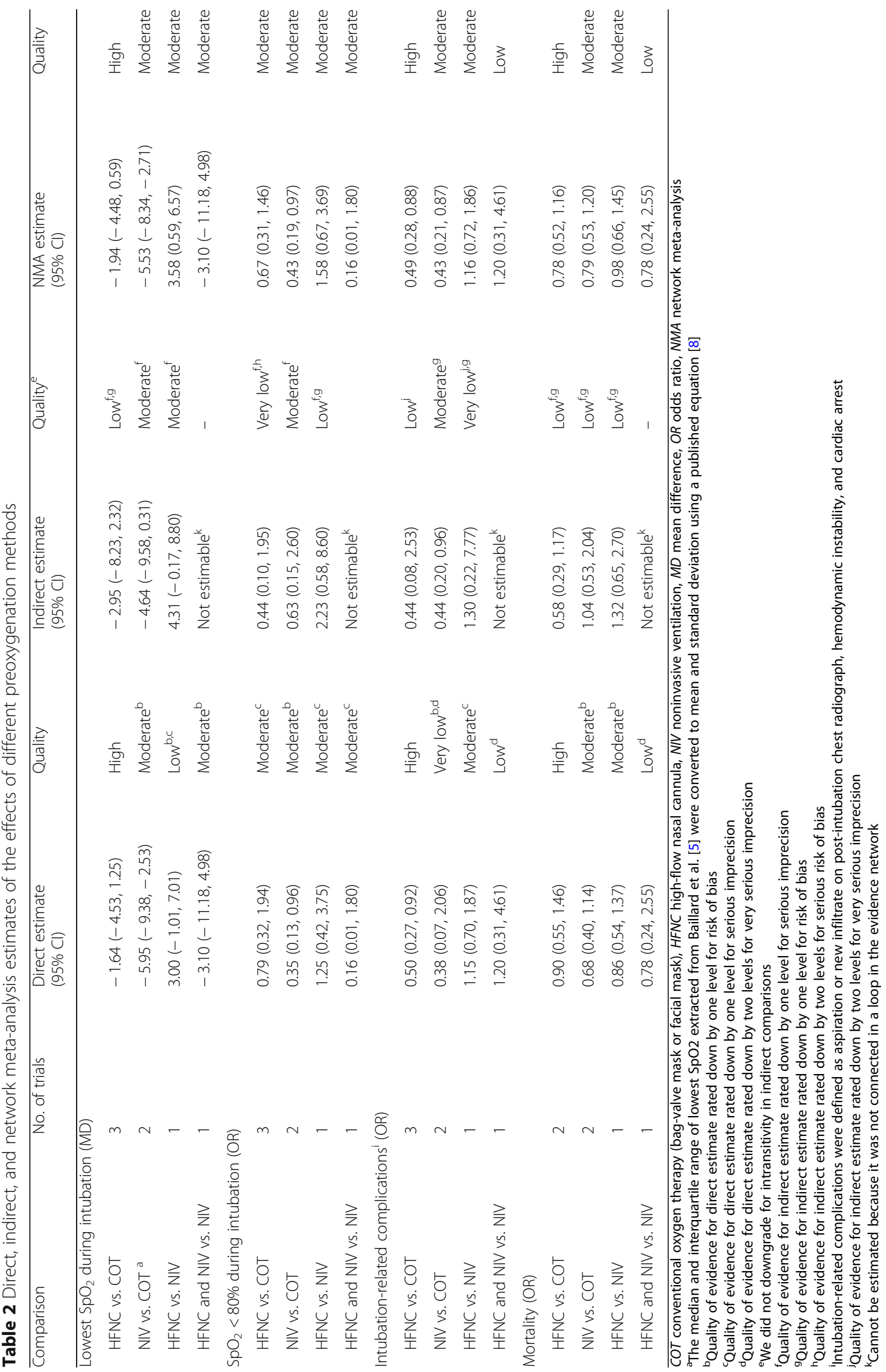




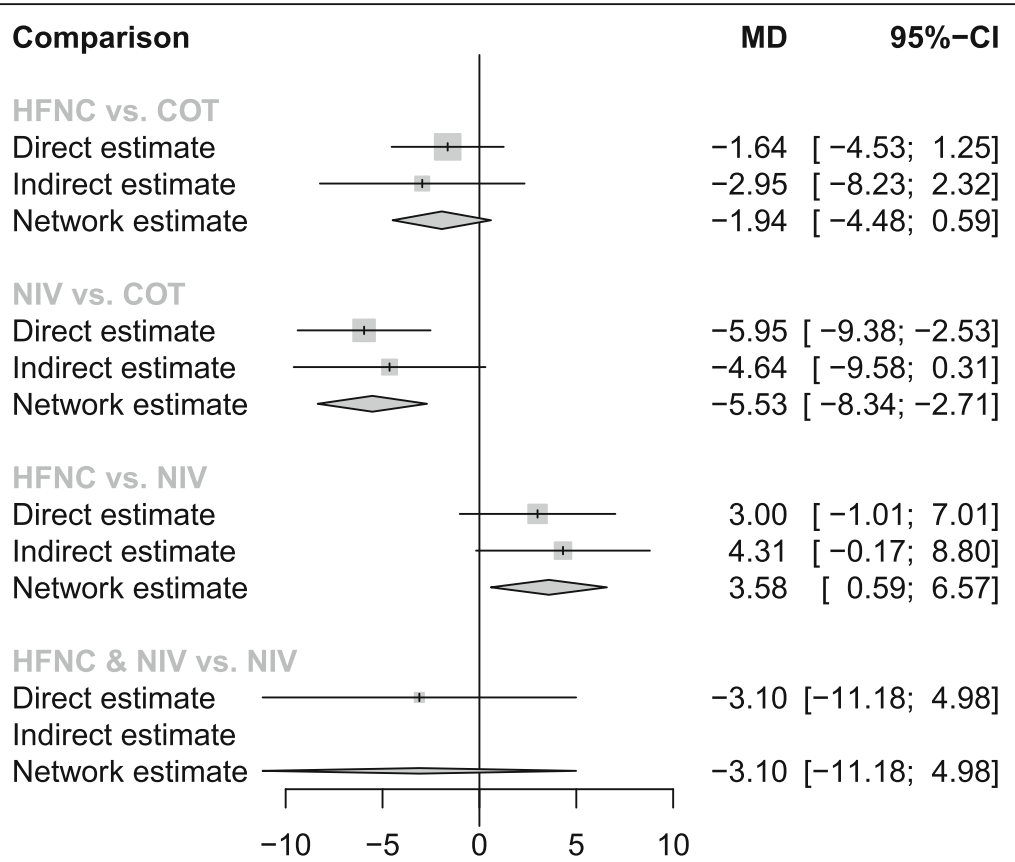

Favour first intervention Favour second intervention

Fig. 3 Forest plot of lowest $\mathrm{SpO}_{2}$ during intubation. $P^{2}=23.6 \%$. Q-statistics for heterogeneity (within designs) and inconsistency (between designs). Total: $p=0.264$, within designs: $p=0.162$, between designs: $p=0.750$. COT, conventional oxygen therapy (bag-valve mask or facial mask); HFNC, high-flow nasal cannula; NIV, noninvasive ventilation; MD, mean difference; NMA, network meta-analysis

\section{Study characteristics}

Of the 7 eligible trials, 3 compared HFNC with COT; 2, NIV with COT; 1 , NIV with HFNC; and 1, HFNC and NIV with NIV (Table 1). Trial sample size ranged from 40 to 313 patients. Results of the individual studies could be found in Additional file 2: Tables S2-S3.

\section{Risk of bias}

The risk of bias was high in 1 trial, low in 3 trials, and with some concerns in 3 trials (Fig. 2).

Table 3 The P-score statistics

\begin{tabular}{lllll}
\hline & HFNC and NIV & NIV & HFNC & COT \\
\hline $\begin{array}{l}\text { Lowest } \mathrm{SpO}_{2} \text { during } \\
\text { intubation }\end{array}$ & 0.895 & 0.739 & 0.336 & 0.030 \\
$\begin{array}{l}\mathrm{SpO}_{2}<80 \% \text { during } \\
\text { intubation }\end{array}$ & 0.957 & 0.634 & 0.344 & 0.066 \\
$\begin{array}{l}\text { Intubation-related } \\
\text { complications }\end{array}$ & 0.560 & 0.774 & 0.595 & 0.071 \\
$\begin{array}{l}\text { Mortality } \\
\text { P-s }\end{array}$ & 0.689 & 0.556 & 0.598 & 0.157
\end{tabular}

$P$-scores represent the extent of certainty that a treatment is better than the other treatments-the $P$-score would be close to 1 when a treatment is certain to be the best and close to 0 when a treatment is certain to be the worst

COT conventional oxygen therapy (bag-valve mask or facial mask), HFNC highflow nasal cannula, NIV noninvasive ventilation, $M D$ mean difference, $O R$ odds ratio, NMA network meta-analysis

\section{Quality of evidence}

Direct comparisons often suffered from imprecision and limitations of risk of bias. There were no significant concerns regarding intransitivity. There was no significant incoherence detected by statistical testing nor visual inspection of direct and indirect estimates (Table 2).

\section{Clinical outcomes}

\section{Lowest $\mathrm{SpO}_{2}$ during intubation}

Seven trials (959 patients) reported the lowest $\mathrm{SpO}_{2}$ during intubation (Additional file 2: Table S2). The network geometry was shown in Additional file 2: Figure S2. The network estimate provided high-to-moderate quality evidence (Table 2). Patients preoxygenated with NIV had significantly less desaturation than patients treated with COT (network estimate, MD 5.53, 95\% CI 2.71, 8.34) and HFNC (network estimate, MD 3.58, 95\% CI 0.59, 6.57) (Fig. 3). Although HFNC and NIV was ranked to be the best treatment (Table 3), there was no evidence that HFNC and NIV was superior than NIV (direct estimate, MD - 3.10, 95\% CI - 11.18, 4.98), and thus, the result should be interpreted with caution. NIV ranked the 2nd among the four methods. The heterogeneity and consistency were low $\left(I^{2}=23.6 \%\right.$; $Q$ statistics total: $p=$ 0.264 , within design: $p=0.162$, between designs: $p=$ $0.750)$. 


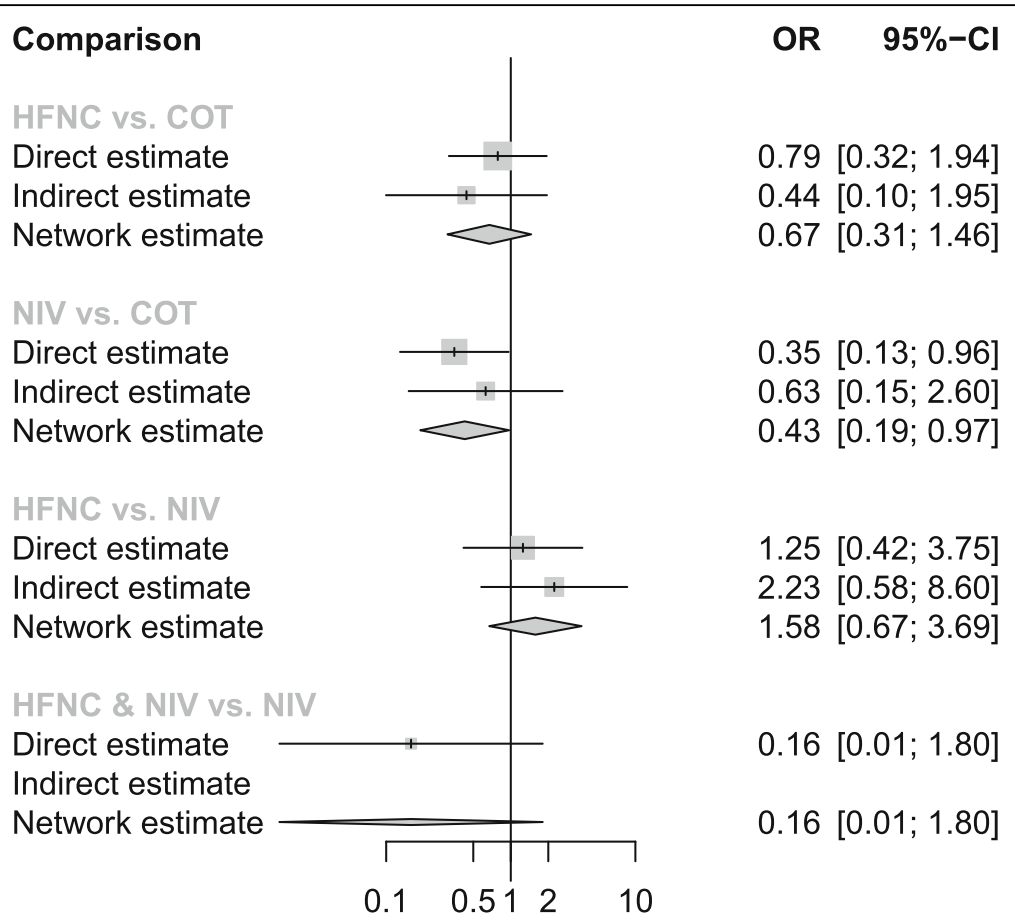

Favour first intervention Favour second intervention

Fig. 4 Forest plot of $\mathrm{SpO}_{2}<80 \%$ during intubation. $P^{2}=48 \%$. Q-statistics for heterogeneity (within designs) and inconsistency (between designs). Total: $p=0.104$, within designs: $p=0.072$, between designs: $p=0.409$. COT, conventional oxygen therapy (bag-valve mask or facial mask); HFNC, high-flow nasal cannula; NIV, noninvasive ventilation; OR, odds ratio; NMA, network meta-analysis

\section{$\mathrm{SpO}_{2}<80 \%$ during intubation}

Seven trials (959 patients) reported the incidence of $\mathrm{SpO}_{2}<80 \%$ during intubation (Additional file 2: Table $\mathrm{S} 2$ ). The network estimate provided moderate-quality evidence (Table 2). Significant desaturation with $\mathrm{SpO}_{2}<$ $80 \%$ was less common in patients preoxygenated with NIV than that with COT (network estimate OR 0.43, $95 \%$ CI 0.19, 0.97) (Fig. 4). The combined use of HFNC and NIV was ranked to be the best preoxygenation method. However, the confidence interval of its treatment effect estimates was very wide because of the small sample size (direct estimate OR 0.16, 95\% CI 0.01, 1.80). NIV ranked the 2nd among the four preoxygenation methods (Table 3).

\section{Intubation-related complications}

Seven trials (959 patients) reported the intubation-related complications) (Additional file 2: Table S3). The network estimate ranged from high- to low-quality evidence (Table 2). Both NIV (network estimate OR 0.43, 95\% CI 0.21, 0.87) and HFNC (network estimate OR $0.49,95 \%$ CI $0.28,0.88$ ) resulted in a lower risk of intubation-related complications than COT (Fig. 5). NIV ranked the 1st and HFNC 2nd among the four preoxygenation methods (Table 3 ).

\section{Mortality}

Six trials (919 patients) reported the mortality (Additional file 2: Table S2). The network estimate ranged from high- to low-quality evidence (Table 2): There was no evidence showing the superiority of one particular preoxygenation method as determined by the confidence interval (Fig. 6). Thus, the ranking by $P$-scores should be interpreted with caution (Table 3).

\section{Sensitivity analysis}

We performed sensitivity analysis by excluding the study by Guitton et al. [5] as subjects with mild hypoxemia were included, compared with the other included studies which recruited subjects with moderate to severe respiratory failure. Results of direct, indirect, and network estimates were similar (Additional file 2: Figures S3-S6). There was no change in ranking based on $P$-scores (Additional file 2: Table S5).

\section{Discussion}

In this network meta-analysis, we included 7 RCTs enrolling 959 patients comparing three preoxygenation methods-COT, HFNC, and NIV. Hypoxemic patients treated with NIV during intubation desaturated less (as reflected by absolute difference of lowest $\mathrm{SpO}_{2}$ and incidence of $\mathrm{SpO}_{2}<80 \%$ ) than those patients treated with 


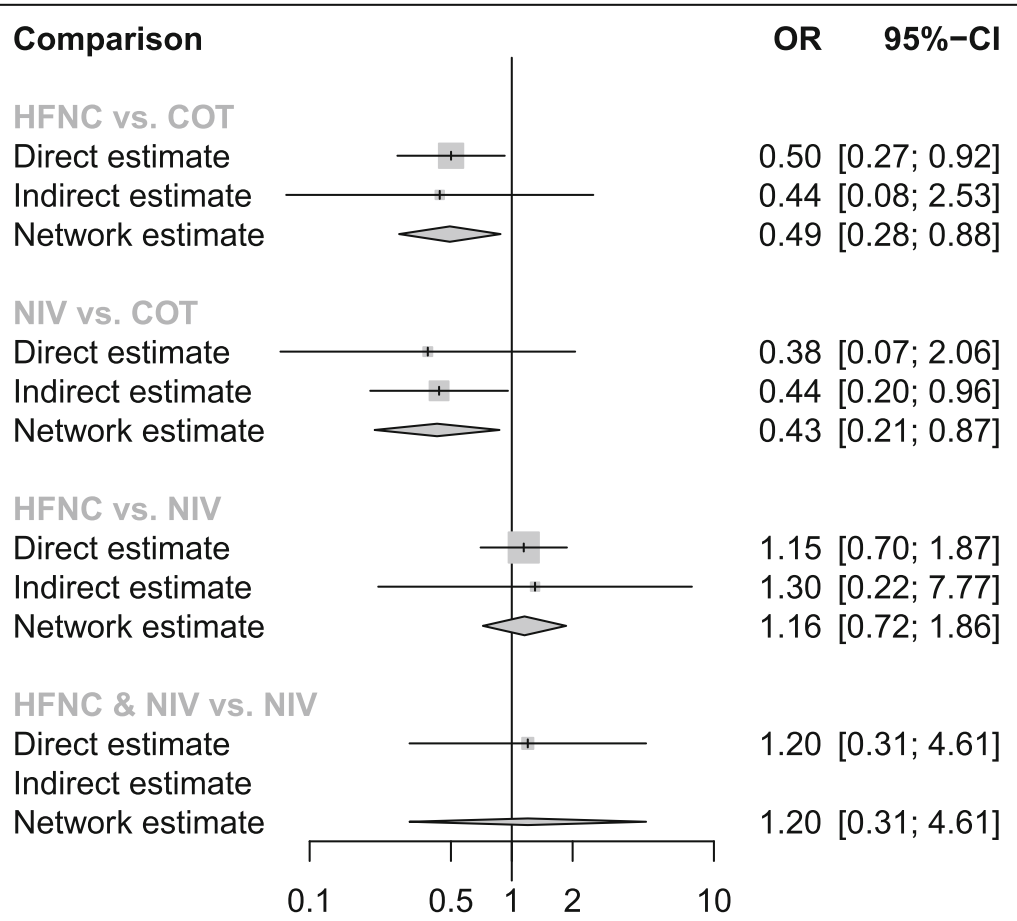

Favour first intervention Favour second intervention

Fig. 5 Forest plot of intubation-related complications. $P^{2}=0 \%$. Q-statistics for heterogeneity (within designs) and inconsistency (between designs). Total: $p=0.978$, within designs: $p=0.914$, between designs: $p=0.892$. Intubation-related complications were defined as aspiration or new infiltrate on post-intubation chest radiograph, hemodynamic instability, and cardiac arrest. COT, conventional oxygen therapy (bag-valve mask or facial mask); HFNC, high-flow nasal cannula; NIV, noninvasive ventilation; OR, odds ratio; NMA, network meta-analysis

HFNC or COT (moderate quality of evidence). The risk of intubation-related complications (aspiration or new infiltrate on postintubation chest radiograph, hemodynamic instability, and cardiac arrest) was lower with NIV than with any other preoxygenation methods (moderate quality of evidence). Among the methods of preoxygenation examined, it seems that combined use of HFNC and NIV is the most effective in minimizing the drop in $\mathrm{SpO}_{2}$ and the incidence of $\mathrm{SpO}_{2}<80 \%$ during intubation. However, this determination is limited to data from only one single-center study in which no head-to-head comparisons were performed against all other methods.

HFNC has several physiological advantages, including its ability to deliver high-flow oxygen, generation of low level of PEEP, and allowing apneic oxygenation [21]. Despite the clear benefit of HFNC in patients with acute hypoxemic respiratory failure and after planned extubation [22, 23], the evidence for HFNC in preoxygenation remains conflicting. The single-center before-after study by Miguel-Montanes et al. [24] has excluded patients with severe hypoxemia. Its positive results have not been reproducible in the subsequent trials by Vourc'h et al. [3] and Simon et al. [4] which recruited patients with severe hypoxemia and patients with mild-moderate hypoxemia respectively. While Guitton et al. [5] have shown a reduction in intubation-related adverse events with the use of HFNC in non-severely hypoxemic patient, it was not accompanied by an improvement in the lowest $\mathrm{SpO}_{2}$. The effectiveness of HFNC is undermined by the loss of PEEP effect due to mouth opening in patients in respiratory distress [25]. These patients can have a dramatic increase in inspiratory nasal and oral flow rate of up to $110 \mathrm{~L} / \mathrm{min}$ and $280 \mathrm{~L} / \mathrm{min}$ respectively, and that could not be matched by the HFNC [26]. Another possible explanation is that apneic oxygenation requires a continuous oxygen extraction from the functional residual capacity (FRC) during the apnea period, thus generating a pressure gradient to allow oxygen flow from the nose into the alveoli. These mechanisms are hindered by the reduction of FRC and shunt physiology in diseased lungs [27]. Airflow may also be limited by the use of cricoid pressure possibly obstructing the space between the oropharynx and trachea [28].

NIV allows the delivery of high level of $\mathrm{FiO}_{2}$ and positive intrathoracic pressure, encouraging alveolar recruitment which could possibly improve the efficiency of gaseous exchange. It has also been shown to counteract inward air leaks and improve face-mask seal [29]. The theoretical risk of gastric distention and aspiration remains unproven based on our analysis. Although the mask must be removed during laryngoscopy, patients 


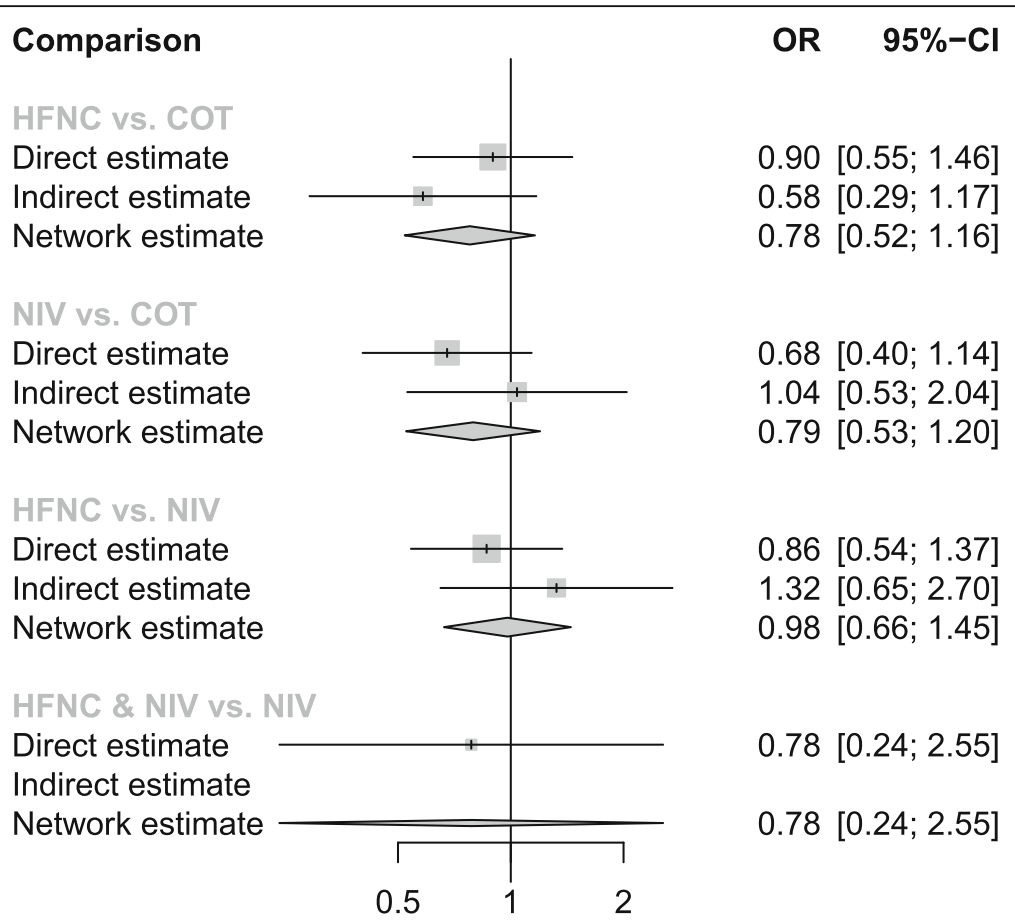

Favour first intervention Favour second intervention

Fig. 6 Forest plot of mortality. $P^{2}=0 \%$. Q-statistics for heterogeneity (within designs) and inconsistency (between designs). Total: $p=0.533$, within designs: $p=0.545$, between designs: $p=0.322$. COT, conventional oxygen therapy (bag-valve mask or facial mask); HFNC, high-flow nasal cannula; NIV, noninvasive ventilation; OR, odds ratio; NMA, network meta-analysis

preoxygenated with NIV still desaturated less during intubation than patients preoxygenated with other modalities. The authors thus recommend the use of NIV for preoxygenation in patients with acute hypoxemic respiratory failure.

The next question would be whether the addition of HFNC to NIV could produce extra benefit during preoxygenation. The pilot study by Jaber et al. [20] published in 2016 showed promising results. However, one must be cautious in the interpretation of the findings in the use of HFNC and NIV, in view of the small sample size that tends to overestimate the treatment effect and the possibility of publication bias. Additionally, the optimal way to minimize air leak with concomitant use of HFNC and NIV has not been well-delineated. It would be interesting to consider whether nasal continuous positive airway pressure mask could play a special role in preoxygenation. Visualization of glottic view by laryngoscopy may be feasible with the nasal mask in situ, maintaining oxygenation during intubation.

Another practical but unaddressed consideration would be the oxygen device used prior to the decision of intubation. Based on the mortality difference shown in FLORALI-1 trial, it would not be surprising to see a surge in the use of HFNC in patients with acute hypoxemic respiratory failure. A more recent systematic review also confirmed a reduced risk of requiring intubation with the use of HFNC compared with COT [22]. All existing studies placed no restriction in the patient enrollment based on the oxygen devices they used prior to inclusion and the number of patients on advanced oxygen device varied across studies (Additional file 2: Table S4). As shown in the study by Baillard et al. [7], there was an increased risk of adverse events including severe desaturation with $\mathrm{SpO}_{2}<80 \%$ in patients initially put on $\mathrm{NIV}$, who were then randomized to receive COT during preoxygenation. It would be uncertain whether the lowered complication risks during preoxygenation with NIV was in fact a reflection of a higher risk of complication in patients "de-escalated" from a more advanced oxygen support (NIV) to a simpler device (COT). Additionally, whether the advantage of oxygenation in NIV would be less evident in patients who were already put on NIV or HFNC remained unclear.

The study is the first systematic review using network meta-analysis to evaluate preoxygenation methods in patients with acute hypoxemic respiratory failure. NMA allows the comparison of multiple preoxygenation methods and increases the precision by combining direct and indirect estimates. Other strengths of this study included the comprehensive search, duplicate and independent citation screening and data abstraction, use of the latest modified 
Cochrane risk of bias assessment tool, and the adherence to the PRISMA-NMA guideline.

This study had some limitations. Despite an extensive literature search, the number of trials for each comparison of preoxygenation methods remained small. Funnel plot was not constructed because of the limited number of studies, so it is not possible to estimate possible publication bias. While pulse oximetry was frequently used as the outcome measure in clinical trials studying preoxygenation, it is, however, not the best surrogate to reflect systematic oxygenation [30]. Arterial oxygen saturation or end-tidal oxygen is more relevant to assess the adequacy of preoxygenation, but they may not be readily available in case of clinical emergency settings.

\section{Conclusions}

In adult patients with acute hypoxemic respiratory failure, NIV is a safe and probably the most effective preoxygenation method. Further research should be performed to evaluate the benefits of the combination strategy of NIV plus HFNC.

\section{Supplementary information}

Supplementary information accompanies this paper at https://doi.org/10. 1186/s13054-019-2596-1.

Additional file 1: PRISMA checklist. (DOCX $23.5 \mathrm{~kb}$ )

Additional file 2: Figure S1. Timing of preoxygenation methods. Figure S2. Network of preoxygenation methods for evaluating lowest $\mathrm{SpO}_{2}$. The size of the nodes was proportional to the number of patients randomized to each preoxygenation methods and thickness of the lines to the number of direct comparisons. Figure S3.Sensitivity analysis of forest plot of lowest $\mathrm{SpO}_{2}$ during intubation. $\left.\right|^{2}=42.6 \%$. Q-statistics for heterogeneity (within designs) and inconsistency (between designs). Total: $p=0.156$, within designs: $p=0.083$, between designs: $p=0.616$. Figure S4. Sensitivity analysis of forest plot of $\mathrm{SpO}_{2}<80 \%$ during intubation. $1^{2}=0 \%$. Q-statistics for heterogeneity (within designs) and inconsistency (between designs). Total: $p=0.574$, within designs: $p=$ 0.354 , between designs: $p=0.615$. Figure S5. Sensitivity analysis of forest plot of intubation-related complications. $1^{2}=0 \%$. Q-statistics for heterogeneity (within designs) and inconsistency (between designs). Total: $p=0.933$, within designs: $p=0.749$, between designs: $p=0.848$ Figure S6. Sensitivity analysis of forest plot of mortality. $\left.\right|^{2}=0 \%$. Qstatistics for heterogeneity (within designs) and inconsistency (between designs). Total: $p=0.574$, within designs: $p=0.354$, between designs: $p=$ 0.615. Table S1. PubMED search strategy. Table S2. Lowest $\mathrm{SpO}_{2}$, incidence of $\mathrm{SpO}_{2}<80 \%$ during intubation, and mortality. NR, not reported; SD, standard deviation. ${ }^{a} \mathrm{ICU}$ mortality. ${ }^{\mathrm{b}} 28$-day mortality. ${ }^{\mathrm{c}}$ Only median and interquartile range were provided in the study: NIV 92 (8498), COT 88 (79-95). Data were transformed into mean and standard deviation using a published equation [12]. Table S3. Intubation-related complications. NR, not reported; COT, conventional oxygen therapy (bagvalve mask or facial mask); HFNC, high-flow nasal cannula; NIV, noninvasive ventilation; ${ }^{a}$ Adverse events including cardiac arrest, hemodynamic instability and aspiration of gastric contents were included as outcome measure and it was reported that there were no adverse events related to intubation in the study. Table S4. Advanced oxygen devices used before study inclusion. NR, not reported; COT, conventional oxygen therapy (bag-valve mask or facial mask); HFNC, high-flow nasal cannula; NIV, noninvasive ventilation. Table S5. P-scores statistics of sensitivity analysis. (DOCX $840 \mathrm{~kb})$
Additional file 2: Figure S1. Timing of preoxygenation methods. Figure S2. Network of preoxygenation methods for evaluating lowest $\mathrm{SpO}_{2}$. The size of the nodes was proportional to the number of patients randomized to each preoxygenation methods and thickness of the lines to the number of direct comparisons. Figure S3.Sensitivity analysis of forest plot of lowest $\mathrm{SpO}_{2}$ during intubation. $\mathrm{I}^{2}=42.6 \%$. Q-statistics for heterogeneity (within designs) and inconsistency (between designs). Total: $p=0.156$, within designs: $p=0.083$, between designs: $p=0.616$. Figure S4. Sensitivity analysis of forest plot of $\mathrm{SpO}_{2}<80 \%$ during intubation. $\left.\right|^{2}=0 \%$. Q-statistics for heterogeneity (within designs) and inconsistency (between designs). Total: $p=0.574$, within designs: $p=$ 0.354, between designs: $p=0.615$. Figure S5. Sensitivity analysis of forest plot of intubation-related complications. I $^{2}=0 \%$. Q-statistics for heterogeneity (within designs) and inconsistency (between designs). Total: $p=0.933$, within designs: $p=0.749$, between designs: $p=0.848$. Figure S6. Sensitivity analysis of forest plot of mortality. $\left.\right|^{2}=0 \%$. statistics for heterogeneity (within designs) and inconsistency (between designs). Total: $p=0.574$, within designs: $p=0.354$, between designs: $p=$ 0.615. Table S1. PubMED search strategy. Table S2. Lowest $\mathrm{SpO}_{2}$, incidence of $\mathrm{SpO}_{2}<80 \%$ during intubation, and mortality. NR, not reported; SD, standard deviation. ${ }^{a} \mathrm{ICU}$ mortality. ${ }^{\mathrm{b}} 28$-day mortality. ${ }^{\mathrm{C}}$ Only median and interquartile range were provided in the study: NIV 92 (8498), COT 88 (79-95). Data were transformed into mean and standard deviation using a published equation [12]. Table S3. Intubation-related complications. NR, not reported; COT, conventional oxygen therapy (bagvalve mask or facial mask); HFNC, high-flow nasal cannula; NIV,

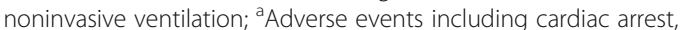
hemodynamic instability and aspiration of gastric contents were included as outcome measure and it was reported that there were no adverse events related to intubation in the study. Table S4. Advanced oxygen devices used before study inclusion. NR, not reported; COT, conventional oxygen therapy (bag-valve mask or facial mask); HFNC, high-flow nasal cannula; NIV, noninvasive ventilation. Table S5. P-scores statistics of sensitivity analysis. (DOCX $840 \mathrm{~kb}$ )

\section{Abbreviations}

COT: Conventional oxygen therapy; NIV: Noninvasive ventilation; HFNC: Highflow nasal cannula; ICU: Intensive care unit; PEEP: Positive end-expiratory pressure; NMA: Network meta-analysis; RCT: Randomized controlled trials; MD: Mean difference; OR: Odds ratio; Cl: Confidence interval; NR: Not reported; RR: Respiratory rate; bpm: Breath per minute; GCS: Glasgow coma scale; RSI: Rapid sequence induction; BVM: Bag-valve mask; SBP: Systolic blood pressure; SOFA: Sequential Organ Failure Assessment; SD: Standard deviation; IQR: Interquartile range

\section{Authors' contributions}

KF conceived the study, performed the literature search, analyzed the data, and drafted the manuscript. SA and GN did the acquisition of data and the revision of the manuscript. All authors read and approved the final manuscript.

\section{Funding}

There is no funding for this review.

\section{Availability of data and materials}

All data generated or analyzed during the present study are included in this published article and its supplementary information files.

Ethics approval and consent to participate

Not applicable

Consent for publication

Not applicable

Competing interests

The authors declare that they have no competing interests. 
Received: 3 June 2019 Accepted: 2 September 2019 Published online: 18 September 2019

\section{References}

1. Russotto V, Cortegiani A, Raineri SM, Gregoretti C, Giarratano A. Respiratory support techniques to avoid desaturation in critically ill patients requiring endotracheal intubation: a systematic review and meta-analysis. J Crit Care. 2017;41:98-106. https://doi.org/10.1016/j.jcrc.2017.05.003.

2. De Jong A, Rolle A, Molinari N, Paugam-Burtz C, Constantin JM, Lefrant JY, Asehnoune K, Jung B, Futier E, Chanques G, Azoulay E, Jaber S. Cardiac arrest and mortality related to intubation procedure in critically ill adult patients: a multicenter cohort study. Crit Care Med. 2018;46(4):532-9. https://doi.org/10.1097/CCM.0000000000002925.

3. Vourc'h M, Asfar P, Volteau C, Bachoumas K, Clavieras N, Egreteau PY, Asehnoune K, Mercat A, Reignier J, Jaber S, Prat G, Roquilly A, Brule N, Villers D, Bretonniere C, Guitton C. High-flow nasal cannula oxygen during endotracheal intubation in hypoxemic patients: a randomized controlled clinical trial. Intensive Care Med. 2015;41(9):1538-48. https://doi.org/10.1007/ s00134-015-3796-z.

4. Simon M, Wachs C, Braune S, de Heer G, Frings D, Kluge S. High-flow nasal cannula versus bag-valve-mask for Preoxygenation before intubation in subjects with hypoxemic respiratory failure. Respir Care. 2016;61(9):1160-7. https://doi.org/10.4187/respcare.04413.

5. Guitton C, Ehrmann S, Volteau C, Colin G, Maamar A, Jean-Michel V, Mahe PJ, Landais M, Brule N, Bretonniere C, Zambon O, Vourc'h M. Nasal highflow preoxygenation for endotracheal intubation in the critically ill patient: a randomized clinical trial. Intensive Care Med. 2019;45(4):447-58. https:// doi.org/10.1007/s00134-019-05529-w.

6. Baillard C, Fosse JP, Sebbane M, Chanques G, Vincent F, Courouble P, Cohen Y, Eledjam JJ, Adnet F, Jaber $\mathrm{S}$. Noninvasive ventilation improves preoxygenation before intubation of hypoxic patients. Am J Respir Crit Care Med. 2006;174(2):171-7. https://doi.org/10.1164/rccm.200509-15070C.

7. Baillard C, Prat G, Jung B, Futier E, Lefrant JY, Vincent F, Hamdi A, Vicaut E, Jaber $\mathrm{S}$. Effect of preoxygenation using non-invasive ventilation before intubation on subsequent organ failures in hypoxaemic patients: a randomised clinical trial. Br J Anaesth. 2018;120(2):361-7. https://doi.org/10. 1016/j.bja.2017.11.067.

8. Frat JP, Ricard JD, Quenot JP, Pichon N, Demoule A, Forel JM, Mira JP, Coudroy R, Berquier G, Voisin B, Colin G, Pons B, Danin PE, Devaquet J, Prat G, Clere-Jehl R, Petitpas F, Vivier E, Razazi K, Nay MA, Souday V, Dellamonica J, Argaud L, Ehrmann S, Gibelin A, Girault C, Andreu P, Vignon P, Dangers L, Ragot S, Thille AW, group F-s, network R. Non-invasive ventilation versus high-flow nasal cannula oxygen therapy with apnoeic oxygenation for preoxygenation before intubation of patients with acute hypoxaemic respiratory failure: a randomised, multicentre, open-label trial. Lancet Respir Med. 2019;7(4):303-12. https://doi.org/10.1016/S2213-2600(19)30048-7.

9. Lee AW. Use of network meta-analysis in systematic reviews: a survey of authors. Syst Rev. 2016;5:8. https://doi.org/10.1186/s13643-015-0174-4.

10. Hutton B, Salanti G, Caldwell DM, Chaimani A, Schmid CH, Cameron C, loannidis JP, Straus S, Thorlund K, Jansen JP, Mulrow C, Catala-Lopez F, Gotzsche PC, Dickersin K, Boutron I, Altman DG, Moher D. The PRISMA extension statement for reporting of systematic reviews incorporating network meta-analyses of health care interventions: checklist and explanations. Ann Intern Med. 2015:162(11):777-84. https://doi.org/10.7326/M14-2385.

11. Higgins JPT SJ, Savović J, Page MJ, Hróbjartsson A, Boutron I, Reeves B, Eldridge $S \mathrm{~A}$ revised tool for assessing risk of bias in randomized trials. In: Chandler J, McKenzie J, Boutron I, Welch V (editors). Cochrane Methods. Cochrane Database of Systematic Reviews 2016, Issue 10 (Suppl 1). doi: https://doi.org/10.1002/14651858.CD201601

12. Wan $X$, Wang W, Liu J, Tong T. Estimating the sample mean and standard deviation from the sample size, median, range and/or interquartile range. BMC Med Res Methodol. 2014;14:135. https://doi.org/10.1186/1471-2288-14-135.

13. Gerta Rucker UK, Jochem Konig, Orestis Efthimiou and Guido Schwarzer (2019) netmeta: network meta-analysis using frequentist methods. R package version 1.0-1.

14. Rucker $G$, Schwarzer $G$. Ranking treatments in frequentist network metaanalysis works without resampling methods. BMC Med Res Methodol. 2015; 15:58. https://doi.org/10.1186/s12874-015-0060-8.

15. Krahn U, Binder $H$, Konig J. A graphical tool for locating inconsistency in network meta-analyses. BMC Med Res Methodol. 2013;13:35. https://doi.org/ 10.1186/1471-2288-13-35.
16. Higgins JP, Jackson D, Barrett JK, Lu G, Ades AE, White IR. Consistency and inconsistency in network meta-analysis: concepts and models for multi-arm studies. Res Synth Methods. 2012;3(2):98-110. https://doi.org/10.1002/jrsm.1044.

17. Puhan MA, Schunemann HJ, Murad MH, Li T, Brignardello-Petersen R, Singh JA, Kessels AG, Guyatt GH, Group GW. A GRADE Working Group approach for rating the quality of treatment effect estimates from network metaanalysis. BMJ. 2014;349:g5630. https://doi.org/10.1136/bmj.g5630.

18. Balshem $H$, Helfand M, Schunemann HJ, Oxman AD, Kunz R, Brozek J, Vist GE, Falck-Ytter Y, Meerpohl J, Norris S, Guyatt GH. GRADE guidelines: 3. Rating the quality of evidence. J Clin Epidemiol. 2011;64(4):401-6. https:// doi.org/10.1016/j.jclinepi.2010.07.015

19. Salanti G, Del Giovane C, Chaimani A, Caldwell DM, Higgins JP. Evaluating the quality of evidence from a network meta-analysis. PLoS One. 2014;9(7): e99682. https://doi.org/10.1371/journal.pone.0099682.

20. Jaber S, Monnin M, Girard M, Conseil M, Cisse M, Carr J, Mahul M, Delay JM, Belafia F, Chanques G, Molinari N, De Jong A. Apnoeic oxygenation via highflow nasal cannula oxygen combined with non-invasive ventilation preoxygenation for intubation in hypoxaemic patients in the intensive care unit: the single-centre, blinded, randomised controlled OPTINIV trial. Intensive Care Med. 2016;42(12):1877-87. https://doi.org/10.1007/s00134-016-4588-9.

21. Cortegiani A, Accurso G, Mercadante S, Giarratano A, Gregoretti C. High flow nasal therapy in perioperative medicine: from operating room to general ward. BMC Anesthesiol. 2018;18(1):166. https://doi.org/10.1186/s12871-018-0623-4.

22. Rochwerg B, Granton D, Wang DX, Helviz Y, Einav S, Frat JP, MekontsoDessap A, Schreiber A, Azoulay E, Mercat A, Demoule A, Lemiale V, Pesenti A, Riviello ED, Mauri T, Mancebo J, Brochard L, Burns K. High flow nasal cannula compared with conventional oxygen therapy for acute hypoxemic respiratory failure: a systematic review and meta-analysis. Intensive Care Med. 2019;45(5):563-72. https://doi.org/10.1007/s00134-019-05590-5.

23. Zhu Y, Yin H, Zhang R, Ye X, Wei J. High-flow nasal cannula oxygen therapy versus conventional oxygen therapy in patients after planned extubation: a systematic review and meta-analysis. Crit Care. 2019;23(1):180. https://doi. org/10.1186/s13054-019-2465-y.

24. Miguel-Montanes R, Hajage D, Messika J, Bertrand F, Gaudry S, Rafat C, Labbe V, Dufour N, Jean-Baptiste S, Bedet A, Dreyfuss D, Ricard JD. Use of high-flow nasal cannula oxygen therapy to prevent desaturation during tracheal intubation of intensive care patients with mild-to-moderate hypoxemia. Crit Care Med. 2015;43(3):574-83. https://doi.org/10.1097/CCM.0000000000000743.

25. Nishimura M. High-flow nasal cannula oxygen therapy in adults: physiological benefits, indication, clinical benefits, and adverse effects. Respir Care. 2016;61(4):529-41. https://doi.org/10.4187/respcare.04577.

26. Tsounis M, Swart KM, Georgalas C, Markou K, Menger DJ. The clinical value of peak nasal inspiratory flow, peak oral inspiratory flow, and the nasal patency index. Laryngoscope. 2014;124(12):2665-9. https://doi.org/10.1002/ lary. 24810 .

27. Mosier JM, Hypes CD, Sakles JC. Understanding preoxygenation and apneic oxygenation during intubation in the critically ill. Intensive Care Med. 2017; 43(2):226-8. https://doi.org/10.1007/s00134-016-4426-0.

28. Wong DT, Yee AJ, Leong SM, Chung F. The effectiveness of apneic oxygenation during tracheal intubation in various clinical settings: a narrative review. Can J Anaesth. 2017;64(4):416-27. https://doi.org/10.1007/ s12630-016-0802-z.

29. Hanouz JL, Le Gall F, Gerard JL, Terzi N, Normand H. Non-invasive positivepressure ventilation with positive end-expiratory pressure counteracts inward air leaks during preoxygenation: a randomised crossover controlled study in healthy volunteers. Br J Anaesth. 2018;120(4):868-73. https://doi. org/10.1016/j.bja.2017.12.002.

30. Perkins GD, McAuley DF, Giles S, Routledge H, Gao F. Do changes in pulse oximeter oxygen saturation predict equivalent changes in arterial oxygen saturation? Crit Care. 2003;7(4):R67. https://doi.org/10.1186/cc2339.

\section{Publisher's Note}

Springer Nature remains neutral with regard to jurisdictional claims in published maps and institutional affiliations. 